\title{
Concentration and Annealing Effects on Luminescence Properties of Ion-Implanted Silica Layers
}

\author{
Roushdey Salh ${ }^{1,2}$ \\ ${ }^{1}$ Institute of Physics, University of Rostock, Universitaetsplatz 3, 18051 Rostock, Germany \\ ${ }^{2}$ Institute of Physics, Johannes Gutenberg University of Mainz, Staudingerweg 7, 55128 Mainz, Germany \\ Correspondence should be addressed to Roushdey Salh, roushdey@dr.com
}

Received 20 October 2010; Accepted 8 January 2011

Academic Editor: R. F. O’Connell

Copyright (C) 2011 Roushdey Salh. This is an open access article distributed under the Creative Commons Attribution License, which permits unrestricted use, distribution, and reproduction in any medium, provided the original work is properly cited.

\begin{abstract}
The development of optoelectronic or even photonic devices based on silicon technology is still a great challenge. Silicon and its oxide do not possess direct optical transitions and, therefore, are not luminescent. The remaining weak light emission is based on intrinsic and extrinsic defect luminescence. Thus the investigations are extended to ion implantation into silica layers, mainly on over-stoichiometric injection or isoelectronic substitution of both the constituents silicon or oxygen, that is, by ions of the group IV $(\mathrm{C}, \mathrm{Si}, \mathrm{Ge}, \mathrm{Sn}, \mathrm{Pb})$ or the group VI $(\mathrm{O}, \mathrm{S}, \mathrm{Se})$. The samples have been used were $500 \mathrm{~nm}$ thick thermally grown amorphous $\mathrm{SiO}_{2}$ layers, wet oxidized at $1100^{\circ} \mathrm{C}$ on a crystalline Si substrate. The ion implantations were performed with different energies but all with a uniform dose of $5 \times 10^{16}$ ions $/ \mathrm{cm}^{2}$. Such implantations produce new luminescence bands, partially with electronic-vibronic transitions and related multimodal spectra. Special interest should be directed to lowdimension nanocluster formation in silica layers. Implantations of group IV elements show a general increase of the luminescence in the violet-blue region and implantations of group VI elements lead to an increase in the yellow-red spectral region. Comparing cathodoluminescence, photoluminescence, and electroluminescence still too small luminescence quantum yields are obtained.
\end{abstract}

\section{Introduction}

Silicon dioxide $\mathrm{SiO}_{2}$ is the most common material in optical fibers [1] as well as appears as an integral part of silicon-based microelectronic devices like metal-oxidesemiconductor (MOS) transistors [2]. However, adding optical functionality to a silicon microelectronic chip is one of the most challenging problems of materials research. This could be possible using silicon itself, in the form of quantum dots dispersed in silicon dioxide matrix. Their net optical gain is of some order as that of direct-bandgap quantum dots [3].

Many authors have implanted several kinds of ions in silica and found that ion implantation led to an increase in refractive index [4] and changes the chemical structure of glass $[5,6]$. In addition to chemical change in structure, ion implantation in silica is always accompanied with the formation of defects, such as $\mathrm{Si}-\mathrm{Si}$ homobonds which are called oxygen-deficient centers (ODCs), paramagnetic $E^{\prime}$ centers, nonbridging oxygen hole centers (NBOHC), and peroxy radicals (PORs), resulting in not only changes in luminescence emission bands but also leading to new luminescence bands especially in the violet (V) or ultraviolet (UV) region [7].

The photoluminescence (PL) bands $4.3 \mathrm{eV}$ and $2.7 \mathrm{eV}$ were investigated by many authors $[8,9]$. These two bands have been attributed to singlet-singlet and triplet-singlet transitions, respectively, in isoelectronically twofold coordinated silicon $(=\mathrm{Si} \bullet \bullet)$, germanium $(=\mathrm{Ge} \bullet \bullet)$, and tin $(=\mathrm{Sn} \bullet \bullet)$ $[7,10]$. A strong violet luminescence band at $3.1 \mathrm{eV}$ is often reported in Ge-doped silica and attributed to the Ge-related oxygen-deficient center (Ge-ODC) [9] or low-dimensional Ge nanoclusters imbedded in the silica matrix [11].

Group IV elements like carbon (C), silicon ( $\mathrm{Si}$ ), germanium $(\mathrm{Ge})$, tin $(\mathrm{Sn})$, and lead $(\mathrm{Pb})$ as well as group VI elements (oxygen $(\mathrm{O})$, sulfur $(\mathrm{S})$, and selenium $(\mathrm{Se})$ ) are mostly substitutional dopants with their influence to silica's natural luminescence defects [12].

The present study is extended to various electronical and optical modifications of amorphous silica layers as they are applied in microelectronics, optoelectronics, as well as in 
the forthcoming photonics. Scanning electron microscopy (SEM), scanning transmission electron microscopy (STEM), and cathodoluminescence (CL) have been used to investigate thermally grown pure amorphous silicon dioxide and ionimplanted layers. The main luminescent centers in silicon dioxide layers are the red luminescence $(1.85 \mathrm{eV})$ of the nonbridging oxygen hole center $(\mathrm{NBOHC}$; $\equiv \mathrm{Si}-\mathrm{O} \bullet$ ), a blue $(2.7 \mathrm{eV})$ and an ultraviolet luminescence $(4.3 \mathrm{eV})$ of the oxygen-deficient centers (ODCs; $\equiv \mathrm{Si} \cdot \cdots \mathrm{Si} \equiv$ ), and a yellow luminescence $(2.2 \mathrm{eV})$ appears especially in hydrogen-treated silica indicating water molecules, and on the other hand, in silicon excess samples indicating higher silicon aggregates. A quite different CL dose behavior of the red luminescence is observed in dry and hydrogen-treated samples due to dissociation and reassociation of mobile hydrogen and oxygen to radicals of the silica network. Additionally implanted hydrogen diminishes the red luminescence in wet oxide but maintains the blue and the UV bands. Thus hydrogen passivates the NBOHC and keeps the ODCs in active emission states. A model of luminescence center transformation is proposed based on radiolytic dissociation and reassociation of mobile oxygen and hydrogen at the centers as well as formation of interstitial $\mathrm{H}_{2}, \mathrm{O}_{2}$, and $\mathrm{H}_{2} \mathrm{O}$ molecules [13].

In light of the reviewed facts, this study was mainly dedicated to investigating irradiation-induced defects in silica network. The experimental techniques, the instrumentations, and sample materials employed to perform this study are given in Section 2. In Section 3 the documentation of the CL spectra of pure $\mathrm{SiO}_{2}$ is presented so it can be used as a basis of the comparison for the ion-implanted silica layers.

\section{Experimental}

Cathodoluminescence spectroscopy is a technique that can provide essential information on the nature of luminescence centers. The emission of photons in cathodoluminescence processes is due to an electronic transition between an initial state and the final state. Conventionally, there are several kinds of cathodoluminescence devices that can be installed in a digital scanning electron microscope (SEM). One of them is a spectrometer-type device, which incorporates a parabolic mirror mounted on the spectrometer port designed for high efficiency of light collection, as used in this study. This specially designed mirror is used for collecting the cathodoluminescence. Despite the high generation factors for the electron-hole pairs, the external photon yield is relatively small. Furthermore, the intensity generated inside the specimen is considerably reduced by absorption in the specimen and by the total reflection at the specimen surface.

One of the fundamental problems in CL measuring technique is therefore how to collect the emitted radiation over the largest possible solid angle with high efficiency. Figure 1 shows a configuration using a parabolic mirror in which the primary electrons (PE) impact on the specimen through a hole in the parabolic mirror. Light quanta emitted into a solid angle $\pi$ can be detected, where the specimen is located almost inside the mirror during the CL measurement

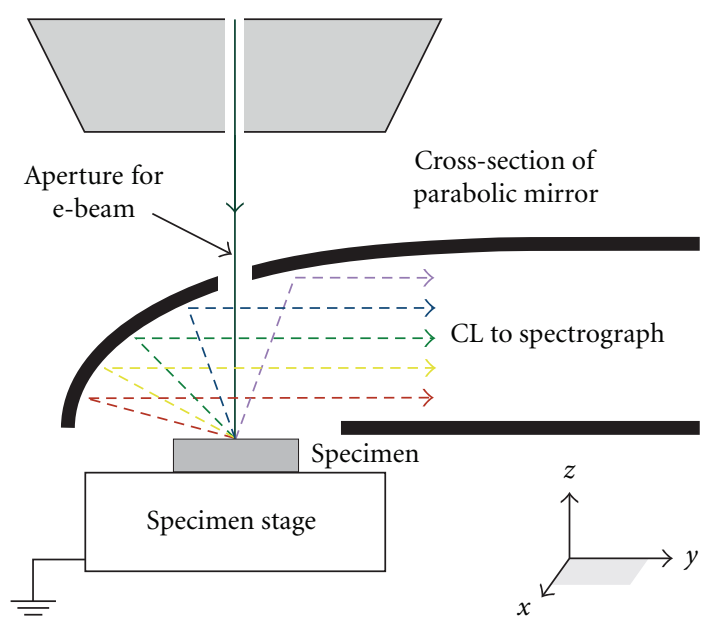

Figure 1: Schematic diagram of the CL collection optics within the SEM (not to scale). The CL photons emitted by the electronirradiated specimen are collected by a parabolic mirror and directed into the spectrograph by an optical guide.

for better CL signal collection. A silica fiber optic transmits the CL light to the entrance slit of grating spectrograph of type Spex-270M and it is registered in a single shot technique by a liquid nitrogen cooled charge coupled device CCD camera (Princeton Instruments, EEV $1024 \times 256$ ) with a spectral resolution of about $4 \mathrm{~nm}$.

The system is controlled by a specially prepped PC. The overall view of the experimental setup is described in detail elsewhere [14]. The CL was excited using a continuous stationary electron beam with energy $E_{o}=10 \mathrm{keV}$ and stable current of $\approx 0.6 \mu \mathrm{A}$ with focused beam diameter of $\approx 1 \mu \mathrm{m}$ in TV scanning mode both at room temperature (RT) and liquid nitrogen temperature (LNT), working distance fixed at $14 \mathrm{~mm}$ where the electron beam was focused on a small area $\left(\approx 100 \times 100 \mu \mathrm{m}^{2}\right)$ of the specimen surface. The CL excitation and recording use the same parameters (experimental conditions) in order to get comparable spectra collected from different silicon dioxide samples. The CL spectra are detected via the parabolic mirror collector, shown in Figure 1, between $1.5 \mathrm{eV}$ and $6.2 \mathrm{eV}$, which is composed of the real luminescence light and the background light produced by the electron beam. The background spectra are registered separately and subtracted from the measured CL signal to eliminate disturbing light radiation from the thermionic cathode and other sources. The background elimination was done periodically by switching the primary electron beam on and off (beam blinking) in each start of new CL measurement. The whole experiment was performed in high vacuum. The overall spectral efficiency of the CL spectra registration shows a nearly constant plateau over the whole UV red region decaying only at the margins $1.5 \mathrm{eV}$ and $6.2 \mathrm{eV}$ to nearly $25 \%$ and $50 \%$, respectively, see $[15,16]$. Thus a correction of directly measured spectra was not necessary and not carried out.

As samples we have used amorphous, thermally grown $\mathrm{SiO}_{2}$ layers, $500 \mathrm{~nm}$ thick, wet oxidized at $1100^{\circ} \mathrm{C}$ on a crystalline Si substrate. The layers are of microelectronic 


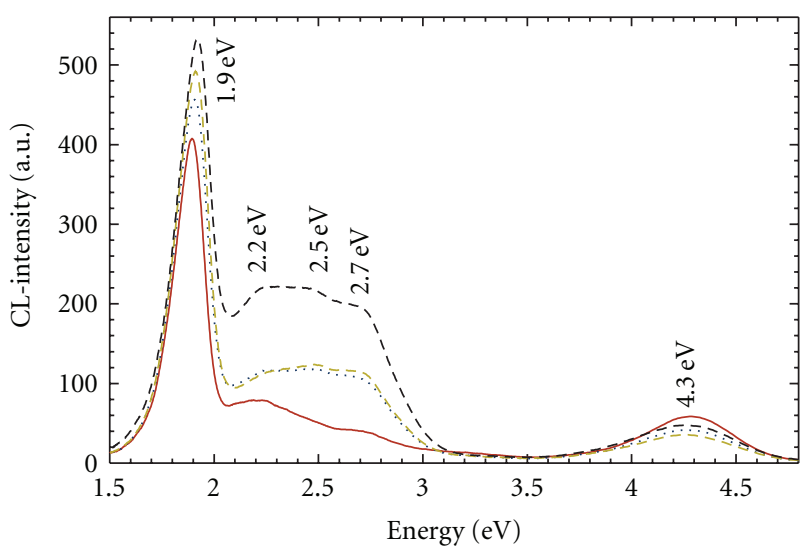

(a)

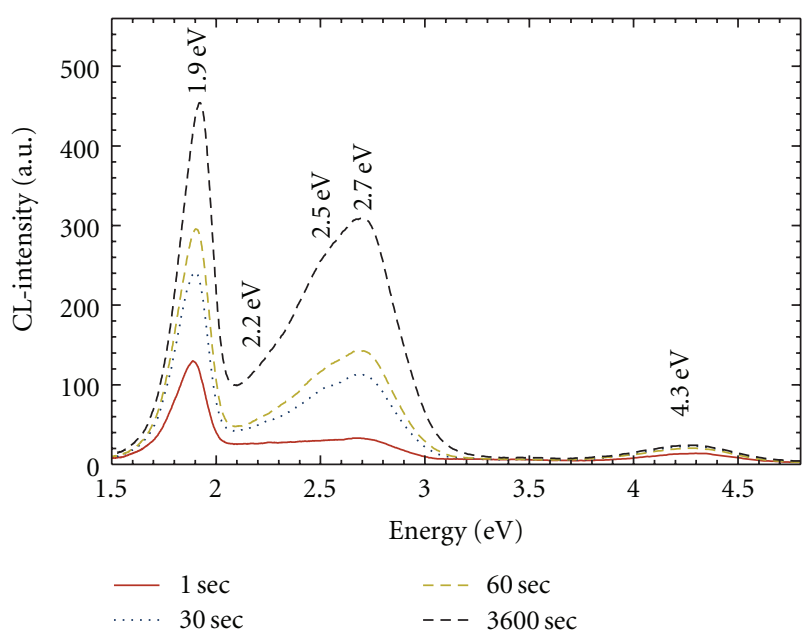

(b)

Figure 2: CL spectra of pure (a) wet and (b) dry $\mathrm{SiO}_{2}$ layers and the intensities of the individual luminescence bands as a function of irradiation time at room temperature.

quality. The ion implantations of $\mathrm{C}^{+}, \mathrm{Si}^{+}, \mathrm{Ge}^{+}, \mathrm{Sn}^{+}, \mathrm{Pb}^{+}$, as well as $\mathrm{O}^{+}, \mathrm{S}^{+}, \mathrm{Se}^{+}$, into these layers were performed with energies of $65,150,350,400,400$, and 100, 150, $330 \mathrm{keV}$, respectively, all with a uniform dose of $5 \times 10^{16}$ ions $/ \mathrm{cm}^{2}$. These implantation energies and doses led to an atomic dopant fraction of about 4 at $\%$ at nearly the half depth of the oxide layers.

A postimplantation thermal annealing was performed at temperature $T_{a}=700-1100^{\circ} \mathrm{C}$ for $1 \mathrm{~h}$ in vacuum. The growth of nanoclusters in the silica matrix has been shown by means of a scanning transmission electron microscope (STEM) (200 keV FEI Tecnai F20). For more details on ion implantation and depth profiling, see $[14,17]$.

\section{Results and Discussion}

Typical CL spectra of dry- and wet-oxidized $\mathrm{SiO}_{2}$ layers measured at room temperature (RT) are shown in Figure 2. Besides the main silica luminescence bands $(1.9 \mathrm{eV}$ the red, $2.7 \mathrm{eV}$ the blue, and $4.3 \mathrm{eV}$ the UV), a yellow band at $2.2 \mathrm{eV}$ has been recognized, increasing at RT after a longer time of irradiation especially in wet oxide [13]. An additional luminescence band can be distinguished in wet oxide silica layer at around $2.5 \mathrm{eV}$. The red and the blue luminescence bands are the most investigated bands in all kinds of silica material, where it is thought that the first one is an oxygen excess-related center and the second one is an oxygen deficiency-related center (ODC) [10].

To investigate whether the different luminescent centers are related to oxygen or to silicon, we have enhanced one or the other constituent and will compare nonstoichiometric $\mathrm{SiO}_{x}$ layers produced by direct oxygen or silicon ion implantation. Moreover, it has been tried to replace oxygen isoelectronically by group VI and silicon by group IV elements.

In Figure 3(a) the spectra of additional oxygen $\mathrm{O}^{+}$implanted silica are shown. The surprisingly novel feature of the spectra appears in their multimodal structure from $1.5 \mathrm{eV}$ up to $2.48 \mathrm{eV}$. An identical multimodal structure, but even sharper and more regular, is found in sulfur $\mathrm{S}^{+}$ implanted layers, as shown in Figure 3(b). Obviously in $\mathrm{S}^{+}$ implanted layers, the high violet band intensity at $3 \mathrm{eV}$ is assigned to sulfur $\mathrm{S}^{+}$implantation. Moreover, the sharp and intense multiple peaks in the region $1.5-2.48 \mathrm{eV}$ are observed for these layers as in $\mathrm{O}^{+}$implanted layers both for room temperature and liquid nitrogen temperature with higher intensity. The exact band positions correspond to almost equidistant energy steps of $140 \mathrm{meV}$ in the green region then slightly decrease to $110 \mathrm{meV}$ in the IR region, as we have already described in $[18,19]$. Thus the mean energy step width is about $120 \mathrm{meV}$.

$\mathrm{Se}^{+}$was isoelectronically implanted with regard to oxygen. Figure 3(c) shows the CL spectra obtained from the $\mathrm{SiO}_{2}$ layers implanted by $\mathrm{Se}^{+}$and annealed at $900^{\circ} \mathrm{C}$. Once again no change is found in the UV luminescence; it is appearing at the same position with low intensity, also the violet luminescence due to $\mathrm{Se}^{+}$implantation this time at $3 \mathrm{eV}$ but with lower intensity. The blue luminescence is also located clearly at $2.7 \mathrm{eV}$. The red and yellow luminescence is enhanced by $\mathrm{Se}^{+}$implantation, and both bands seem to be from the same origin as in pure $\mathrm{SiO}_{2}$ where both have the same tendency during electron beam irradiation. However, in $\mathrm{Se}^{+}$-implanted layers, the multimodal structure does not appear. As possible reason for this disagreement can be that the defects caused by $\mathrm{Se}^{+}$implantation have reasonably shorter life time than as in the case of $\mathrm{O}^{+}$or $\mathrm{S}^{+}$implantation where the duration of the collection of the first spectra is $1 \mathrm{sec}$. This time could be sufficiently long to fail to notice the multimodal structure; further experiments are in progress to reduce the measurement time.

As already expressed, we see identical multimodal structured luminescence in sulfur-implanted silica layers as well as in additional oxygen-implanted samples. Because overstoichiometric $\mathrm{SiO}_{x}$ with $x>2$ does not exist [20], we may assume oxygen on interstitial sites of the $\mathrm{SiO}_{2}$ network. Even in nonirradiated and neutron and gamma-irradiated wet and dry silica glasses and $a$-quartz a considerable amount of interstitial $\mathrm{O}_{2}$ molecules was found by IR photoluminescence, exceeding from $10^{13}$ to $8 \times 10^{17}$ molecules $/ \mathrm{cm}^{3}$ [21]. 


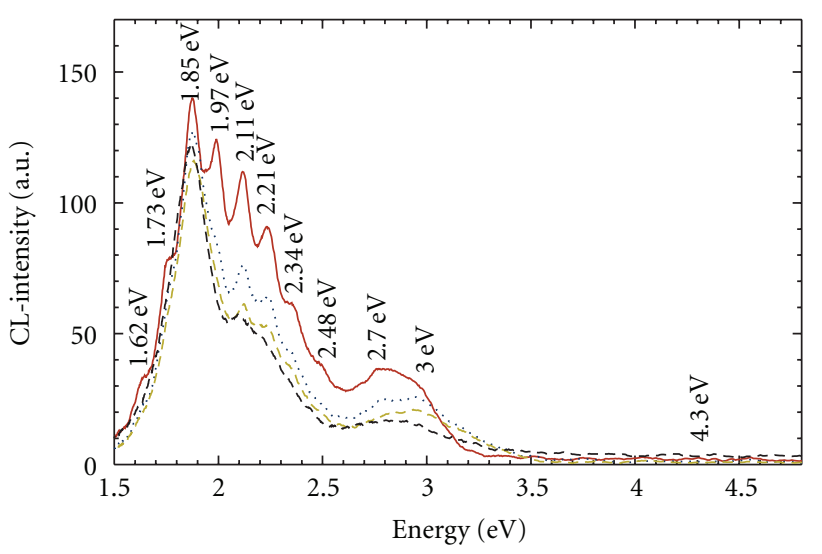

(a)

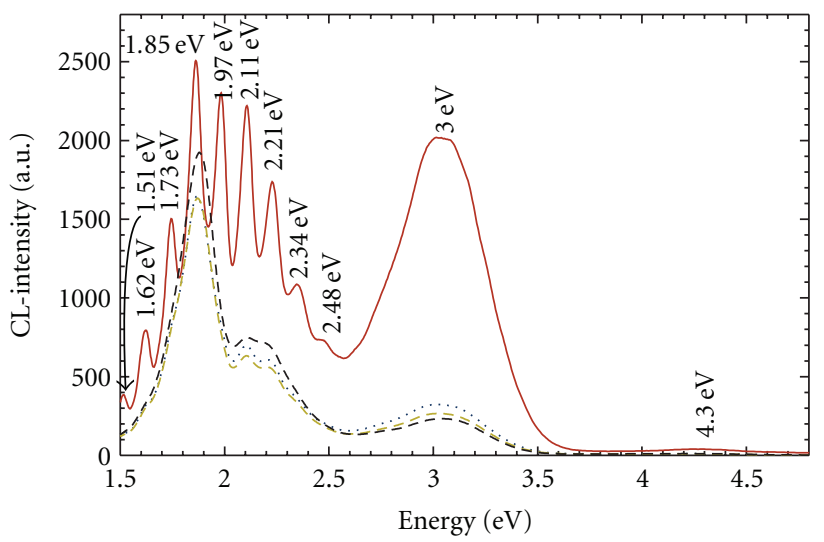

(b)

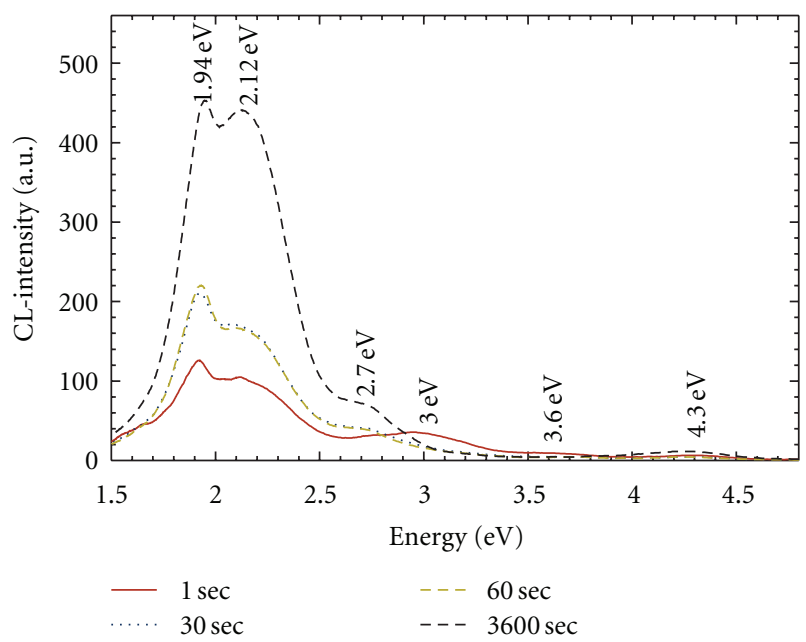

(c)

FIgURE 3: Room temperature CL spectra of (a) $\mathrm{O}^{+}$, (b) $\mathrm{S}^{+}$, (c) $\mathrm{Se}^{+}$implanted $\mathrm{SiO}_{2}$ layers with thicknesses $d_{o x}=500 \mathrm{~nm}$ and implantation doses $D=5 \times 10^{16} \mathrm{~cm}^{-2}$. After ion implantation, the samples were thermally post-annealed at $T_{a}=900^{\circ} \mathrm{C}$.

On the other hand, in $\mathrm{SiO}_{2}: \mathrm{S}^{+}$, sulfur atoms are supposed to substitute oxygen in the $\mathrm{SiO}_{2}$ matrix, and then more oxygen in interstitial sites is expected too. It should be a direct evidence for oxygen as the origin of the multimodal spectra. So we may state the following: while the same multimodal structure is found in oxygen as well as sulfur-implanted $\mathrm{SiO}_{2}$ layers, it is leading to the conclusion that not sulfur but oxygen is the source of these multiple spectra.

Looking to the literature, we found excitation [22] and emission spectra [23] of the negatively charged molecule $\mathrm{O}_{2}{ }^{-}$ on interstitial sites in alkali halide crystals. The ground electronic state and several low-lying excited states of the superoxide ion $\mathrm{O}_{2}{ }^{-}$have been studied by multiconfiguration selfconsistence fields (MCSCFs) [23]. All is in good agreement with our CL spectra of $\mathrm{SiO}_{2}: \mathrm{O}^{+}$and $\mathrm{SiO}_{2}: \mathrm{S}^{+}$layers. Thus we favor the interstitial $\mathrm{O}_{2}{ }^{-}$molecule on interstitial sites for the multimodal luminescence spectra $[8,24]$.

As a result of comparison between the CL spectra of the pure and $\mathrm{Si}^{+}$-implanted $\mathrm{SiO}_{2}$ (Figure 4(a)), one can see a significant blue luminescence emission $2.7 \mathrm{eV}$ and an intense broad luminescent band in the green-yellow region between $2.2 \mathrm{eV}$ and $2.5 \mathrm{eV}$ which are observed especially after annealing at high temperature $\left(T_{a}=900^{\circ} \mathrm{C}\right)$. The ultraviolet $(4.3 \mathrm{eV})$ and the red luminescence $(1.9 \mathrm{eV})$ are also present but with less influence due to silicon implantation. Two additional luminescence bands can be anticipated, one in the green $\mathrm{G}$ region at $2.5 \mathrm{eV}$ and another in the red region at around $1.65 \mathrm{eV}$. Higher initial intensities in the thermally annealed samples were registered but all luminescence were saturated to the same level as of the nonannealed samples. The green $2.5 \mathrm{eV}$, yellow $2.2 \mathrm{eV}$, and the additional red $1.65 \mathrm{eV}$ emission bands are associated with the presence of silicon nanoclusters in the silica matrix $[14,25]$. The presence of silicon nanoclusters (crystalline and amorphous) is confirmed by transmission electron microscopy (TEM) and by means of EDX measurements [25].

The spectra of $\mathrm{C}^{+}$-implanted $\mathrm{SiO}_{2}$ (Figure 4(b)), is more similar to the CL spectra of $\mathrm{Si}^{+}$. The only difference between the CL spectra of $\mathrm{Si}^{+}$- and $\mathrm{C}^{+}$-implanted samples is that two additional luminescence bands in $\mathrm{UV}$ and $\mathrm{V}$ regions are excited. One is at $3.8 \mathrm{eV}$ and the other at around $3.1 \mathrm{eV}$. Luminescence at $3.8 \mathrm{eV}$ is reported in crystalline $\mathrm{SiO}_{2}$ coated with LiNbO3 [26], but never in normal or carbon-implanted silica. The intense luminescent bands from the blue up to the yellow spectral region as a result of $\mathrm{C}^{+}$ion-implantation processes into $\mathrm{SiO}_{2}$ layers have been reported by several authors [27-29]. There is a general consensus in assigning these bands to the formation of C-related nanoparticles. The green-yellow luminescence band $(2.0-2.2 \mathrm{eV})$ was also observed in the $\mathrm{C}^{+}$-implanted $\mathrm{SiO}_{2}$ layers. In this case, the intensity of the luminescent band was well correlated with the contribution of carbon-related nanoclusters. A luminescence band at higher energies, in the range of $2.7 \mathrm{eV}$, has also been reported from carbon graphite-like nanoparticles embedded in $\mathrm{SiO}_{2}$ layers synthesized either by ion implantation $[28,30]$ or by sputtering deposition of C-rich oxides [31] followed by thermal annealing. The blue luminescent band is also characteristic of SiC-related crystalline nanostructures, as porous $\mathrm{SiC}$ [32]. The microstructure of carbon-implanted silica was investigated by Auger electron spectroscopy (AES) and transmission electron microscopy (TEM). Amorphous nanostructures with a size between 2 and $3.5 \mathrm{~nm}$ were found in a depth region between 80 and $150 \mathrm{~nm}$ below the oxide surface. Strong photoluminescence (PL) around $2.2 \mathrm{eV}$ and 


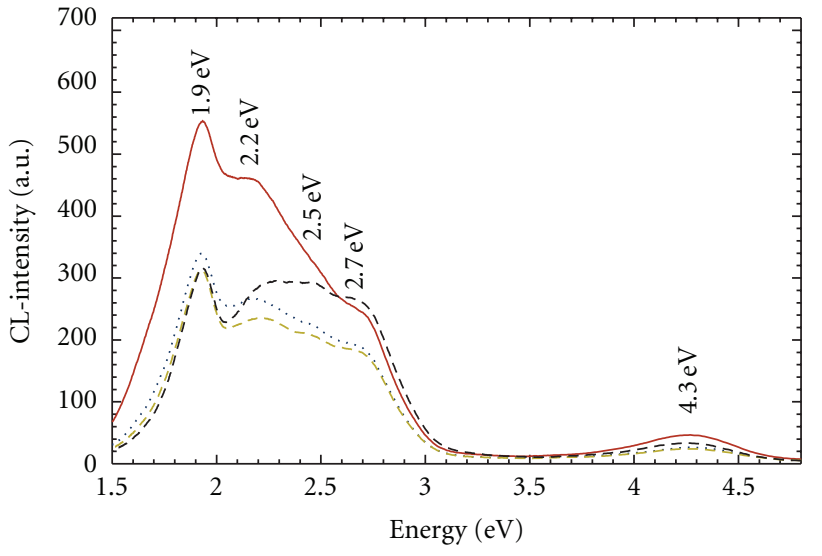

(a)

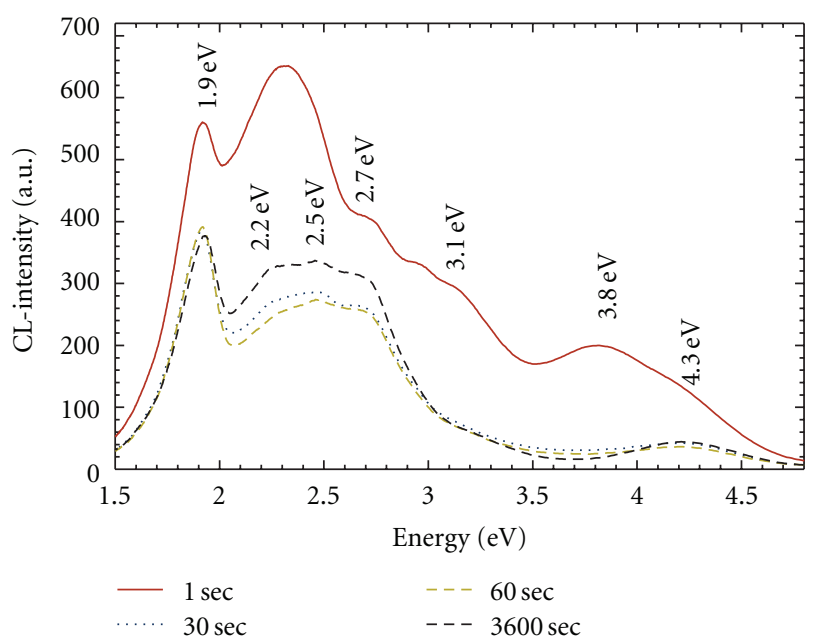

(b)

FIgURE 4: Room temperature CL spectra of (a) $\mathrm{Si}^{+}$, (b) $\mathrm{C}^{+}$ implanted $\mathrm{SiO}_{2}$ layers with thicknesses $d_{o x}=500 \mathrm{~nm}$ and implantation doses $D=5 \times 10^{16} \mathrm{~cm}^{-2}$. After ion implantation, the samples were thermally post-annealed at $T_{a}=900^{\circ} \mathrm{C}$.

$2.7 \mathrm{eV}$ has also been observed after excitation at $4.77 \mathrm{eV}$ as an indication of nanoclusters [29].

The CL spectrum of the $\mathrm{Pb}^{+}-, \mathrm{Sn}^{+}$- and $\mathrm{Ge}^{+}$-implanted sample is shown in Figures 5(a), 5(b), and 5(c). Both Sn and $\mathrm{Pb}$ are classified as metallic substances in contrast to the other dopands. $\mathrm{Pb}^{+}$and $\mathrm{Sn}^{+}$implantation creates defect centers providing more intense luminescence in the violetblue region. Here, two UV bands are detected; one is the $\mathrm{UV}$ of the $\mathrm{SiO}_{2}$ matrix at $4.3 \mathrm{eV}$ with very low intensity and another, for sure due to $\mathrm{Pb}^{+}$implantation at $3.5 \mathrm{eV}$. We were anticipating the existence of a luminescence band at exactly at $2.5 \mathrm{eV}$ and even in pure $\mathrm{SiO}_{2}$. $\mathrm{Pb}^{+}$implantation enhanced this band significantly.

The huge violet luminescence around $3.1 \mathrm{eV}$ in $\mathrm{Ge}^{+}-$ implanted silica appears explicitly after thermal postannealing at temperatures $T_{a}=800-900^{\circ} \mathrm{C}$, see Figure 6. This annealing temperature behavior of the violet luminescence should be correlated with scanning transmission electron microscopy investigations, see Figure 7 and [33]. The nanocluster sizes are growing with annealing temperature and

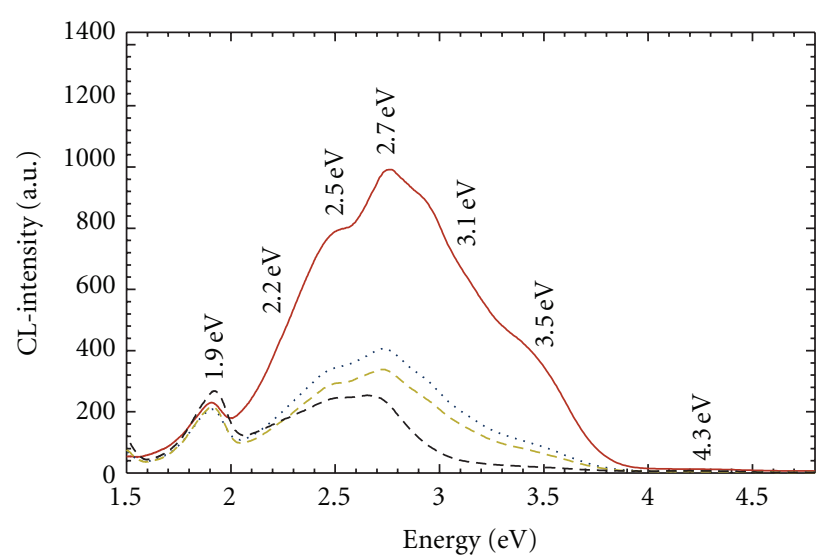

(a)

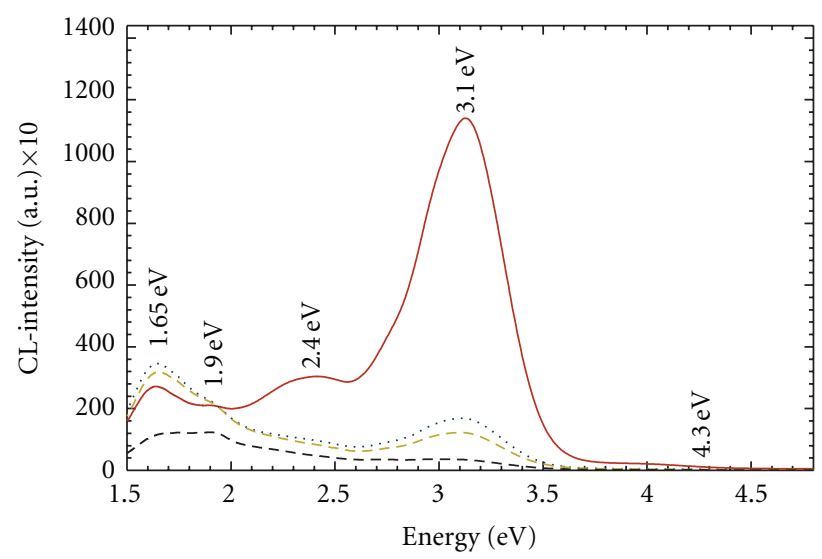

(b)

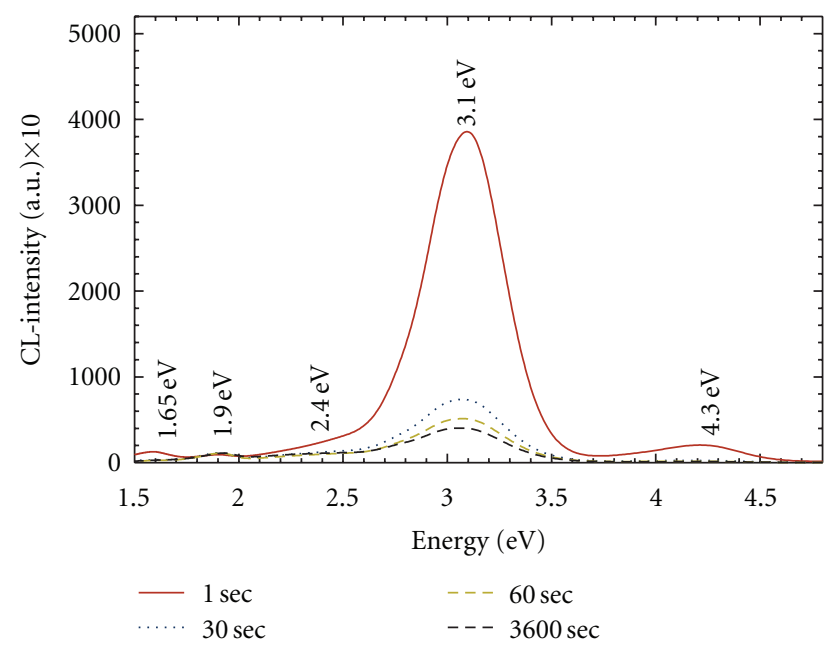

(c)

Figure 5: Room temperature CL spectra of (a) $\mathrm{Pb}^{+}$, (b) $\mathrm{Sn}^{+}$, (c) $\mathrm{Ge}^{+}$implanted $\mathrm{SiO}_{2}$ layers with thicknesses $d_{o x}=500 \mathrm{~nm}$ and implantation doses $D=5 \times 10^{16} \mathrm{~cm}^{-2}$. After ion implantation, the samples were thermally post-annealed at $T_{a}=900^{\circ} \mathrm{C}$.

distributed from 1 to $7 \mathrm{~nm}$ with a maximum of $3 \mathrm{~nm}$ at $T_{a}=900^{\circ} \mathrm{C}$ and $2-12 \mathrm{~nm}$ with a maximum of $6 \mathrm{~nm}$ at $T_{a}=$ $1100^{\circ} \mathrm{C}$. The corresponding cluster concentrations are $N_{c}=$ $4.6 \times 10^{17}$ and $2.6 \times 10^{17} \mathrm{~cm}^{-3}$ for $T_{a}=900$ and $1100^{\circ} \mathrm{C}$, 


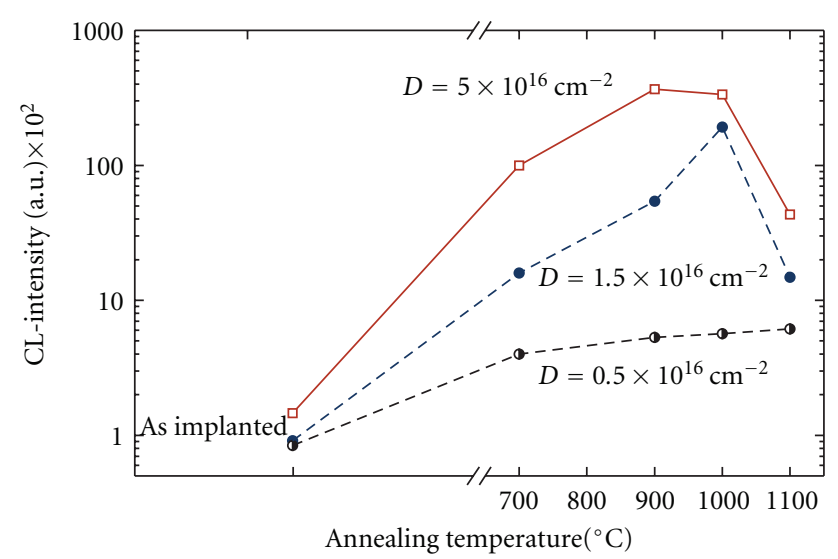

Figure 6: CL intensities of the violet band $3.1 \mathrm{eV}$ in $\mathrm{Ge}^{+}$-implanted silica passing a maximum at $T_{a}=900-1000^{\circ} \mathrm{C}$; DGe: implantation dose.

respectively. Thus, the dispersed Ge atoms will aggregate to clusters via the scenario dimers, trimers, and higher aggregates like hexamer rings as a the first step of cluster formation. Recent three-dimensional plasmon-filtered TEM imaging of such nanoparticles embedded in silica show a more nonspherical shape of these clusters, sometimes like "peanut" shape [34]. These findings should affect quantumconfined luminescence and may explain the unusual broad IR luminescence bands of these samples as quoted already in [33]. In this context it should be mentioned that the strong stable violet $(3.1 \mathrm{eV})$ luminescence of $\mathrm{SiO}_{2}$ : $\mathrm{Ge}$ is not related to quantum confinement of these higher Ge clusters but related to low-dimensional aggregates like the Ge dimers (ODC) or trimers up to hexamer rings [17].

\section{Conclusions}

Ion implantations of group IV elements $(\mathrm{C}, \mathrm{Ge}, \mathrm{Sn}, \mathrm{Pb})$ which are thought to substitute $\mathrm{Si}$ isoelectronically in silica matrix, show new bands and a general increase of the luminescence in the violet-blue region. On the other hand, implantations of oxygen substituting elements of group VI $(\mathrm{S}, \mathrm{Se})$ lead to an increase in the yellow-red spectral region.

As a surprising peculiarity, the cathodoluminescence spectra of oxygen- and sulfur-implanted $\mathrm{SiO}_{2}$ layers show a sharp and intensive multimodal structure between $1.5 \mathrm{eV}$ and $2.48 \mathrm{eV}$. The energy step differences of the sublevels amount to an average of $120 \mathrm{meV}$ and indicate vibronicelectronic transitions, probably, of $\mathrm{O}_{2}{ }^{-}$interstitial molecules, as we could demonstrate by a respective configuration coordinate model $[19,24]$.

In $\mathrm{Ge}^{+}$-implanted $\mathrm{SiO}_{2}$ a strong violet band $(3.1 \mathrm{eV})$ appears and is associated with the Ge-related oxygendeficient center (Ge-ODC). It dominates the luminescence spectra, covering the original blue band (B) (Si-ODC) of the $\mathrm{SiO}_{2}$ matrix. Further on, this band shows a huge increase after thermal annealing around temperatures of $T_{a}=900^{\circ} \mathrm{C}$ by more than two orders of magnitude. Thus the Si-ODCs as well as the Ge-ODCs are formed by $\mathrm{Si}$ and Ge molecules

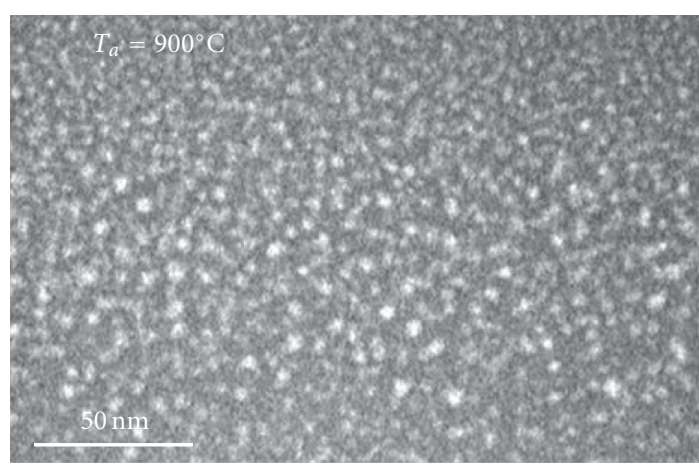

(a)

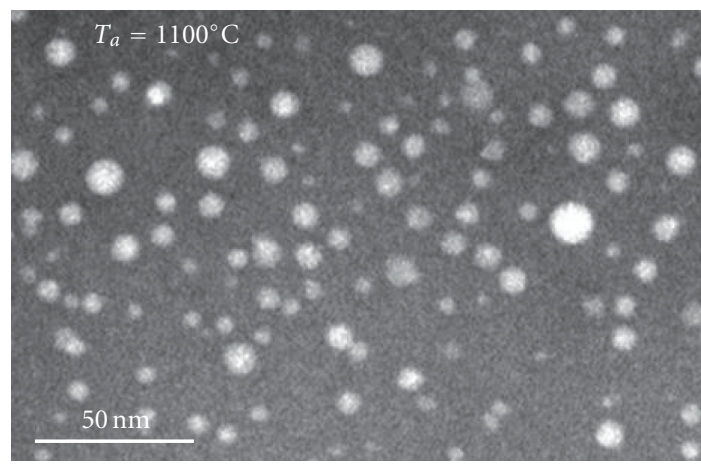

(b)

FIGURE 7: STEM cross-section images of $\mathrm{Ge}^{+}$-implanted $\mathrm{SiO}_{2}$ layers showing cluster growth with increasing annealing temperatures $T_{a}$.

clustering to certain low-dimension fragments like dimers, trimers and up to higher aggregates like hexamer rings [14]. With further thermal annealing at higher temperatures $T_{a}=$ $1000^{\circ} \mathrm{C}$, Si and Ge nanocrystals are formed embedded in the amorphous $\mathrm{SiO}_{2}$ matrix. The nanocluster sizes grow with annealing temperature from $1-7 \mathrm{~nm}$ at $T_{a}=900^{\circ} \mathrm{C}$ to $2-$ $12 \mathrm{~nm}$ at $T_{a}=1100^{\circ} \mathrm{C}$ producing then new luminescence bands in the near-IR region, then partly related to quantum confinement effects [33].

\section{References}

[1] I. Fanderlik, Silica Glass and Its Application, Elsevier, Amsterdam, The Netherlands, 1991.

[2] E. H. Nicollian and J. R. Brews, MOS (Metal Oxide Semiconductor) Physics and Technology, Wiley, New York, NY, USA, 1982.

[3] L. Pavesi, L. Dal Negro, C. Mazzoleni, G. Franzò, and F. Priolo, "Optical gain in silicon nanocrystals," Nature, vol. 408, no. 6811, pp. 440-444, 2000.

[4] P. D. Townsend, "Optical effects of ion implantation," Reports on Progress in Physics, vol. 50, no. 5, pp. 501-558, 1987.

[5] H. Hosono and R. A. Weeks, "Structural defects in chromiumion-implanted vitreous silica," Physical Review B, vol. 40, no. 15, pp. 10543-10549, 1989.

[6] Y. Morimoto, R. A. Weeks, A. V. Barnes, N. H. Tolk, and R. A. Zuhr, "The effect of ion implantation on luminescence of a silica," Journal of Non-Crystalline Solids, vol. 196, pp. 106-112, 1996. 
[7] L. Skuja, "Isoelectronic series of twofold coordinated Si, Ge, and $\mathrm{Sn}$ atoms in glassy $\mathrm{SiO}_{2}$ : a luminescence study," Journal of Non-Crystalline Solids, vol. 149, no. 1-2, pp. 77-95, 1992.

[8] M. Cannas, S. Agnello, R. Boscaino, F. M. Gelardi, S. Grandi, and P. C. Mustarelli, "Ultraviolet emission lifetime in Si and Ge oxygen deficient centers in silica," Journal of NonCrystalline Solids, vol. 322, no. 1-3, pp. 129-133, 2003.

[9] A. Trukhin and B. Poumellec, "Photosensitivity of silica glass with germanium studied by photoinduced of thermally stimulated luminescence with vacuum ultraviolet radiation," Journal of Non-Crystalline Solids, vol. 324, no. 1-2, pp. 21-28, 2003.

[10] L. Skuja, "Section 1. Defect studies in vitreous silica and related materials: optically active oxygen-deficiency-related centers in amorphous silicon dioxide," Journal of NonCrystalline Solids, vol. 239, no. 1-3, pp. 16-48, 1998.

[11] L. Rebohle, T. Gebel, J. Von Borany et al., "Transient behavior of the strong violet electroluminescence of Ge-implanted $\mathrm{SiO}_{2}$ layers," Applied Physics B, vol. 74, no. 1, pp. 53-56, 2002.

[12] R. Salh, L. Fitting Kourkoutis, B. Schmidt, and H. J. Fitting, "Luminescence of isoelectronically ion-implanted $\mathrm{SiO}_{2}$ layers," Physica Status Solidi (A), vol. 204, no. 9, pp. 3132-3144, 2007.

[13] H. J. Fitting, T. Ziems, R. Salh et al., "Cathodoluminescence of wet, dry, and hydrogen-implanted silica films," Journal of NonCrystalline Solids, vol. 351, no. 27-29, pp. 2251-2262, 2005.

[14] R. Salh, A. Von Czarnowski, M. V. Zamoryanskaya, E. V. Kolesnikova, and H. J. Fitting, "Cathodoluminescence of $\mathrm{SiO}_{x}$ under-stoichiometric silica layers," Physica Status Solidi (A), vol. 203, no. 8, pp. 2049-2057, 2006.

[15] M. Goldberg, Cathodoluminescence and cathode-electroluminescence of $\mathrm{SiO}_{2}$ layers, Ph.D. thesis, University of Rostock, 1996.

[16] R. Salh, Luminescent defects in the molecular network of $\mathrm{SiO}_{2}$, Ph.D. thesis, University of Rostock, 2006.

[17] H. J. Fitting, T. Barfels, A. N. Trukhin, B. Schmidt, A. Gulans, and A. Von Czarnowski, "Cathodoluminescence of $\mathrm{Ge}^{+}, \mathrm{Si}^{+}$, and $\mathrm{O}^{+}$implanted $\mathrm{SiO}_{2}$ layers and the role of mobile oxygen in defect transformations," Journal of Non-Crystalline Solids, vol. 303, no. 2, pp. 218-231, 2002.

[18] R. Salh, B. Schmidt, and H. J. Fitting, "Multiplet luminescence of sulfur implanted silica- $\mathrm{SiO}_{2}$ :S," Physica Status Solidi (A), vol. 202, no. 5, pp. R53-R55, 2005.

[19] H. J. Fitting, R. Salh, T. Barfels, and B. Schmidt, "Multimodal luminescence spectra of ion-implanted silica," Physica Status Solidi (A), vol. 202, no. 13, pp. R142-R144, 2005.

[20] C. R. Helm and B. E. Deal, Eds., The Physics and Chemistry of $\mathrm{SiO}_{2}$ and the $\mathrm{Si}_{-} \mathrm{SiO}_{2}$ Interface, Plenum, New York, NY, USA, 1993.

[21] L. Skuja, B. Güttler, D. Schiel, and A. R. Silin, "Infrared photoluminescence of preexisting or irradiation-induced interstitial oxygen molecules in glassy $\mathrm{SiO}_{2}$ and $\alpha$-quartz," Physical Review B, vol. 58, no. 21, pp. 14296-14304, 1998.

[22] J. Rolfe, "First excited state of the O ion," The Journal of Chemical Physics, vol. 70, no. 5, pp. 2463-2465, 1979.

[23] C. S. Ewig and J. Tellinghuisen, "Ab initio study of the electronic states of $\mathrm{O}$ in vacuo and in simulated ionic solids," The Journal of Chemical Physics, vol. 95, no. 2, pp. 1097-1106, 1991.

[24] H. J. Fitting, R. Salh, and B. Schmidt, "Multimodal electronicvibronic spectra of luminescence in ion-implanted silica layers," Journal of Luminescence, vol. 122-123, no. 1-2, pp. 743746, 2007.
[25] E. V. Kolesnikova, A. A. Sitnikova, V. I. Sokolov, and M. V. Zamoryanskaya, "Modification of silicon oxide by high energy electron beam," Diffusion and Defect Data B, vol. 108-109, pp. 729-734, 2005.

[26] G. G. Siu, X. L. Wu, Y. Gu, and X. M. Bao, "Ultraviolet and blue emission from crystalline $\mathrm{SiO}_{2}$ coated with $\mathrm{LiNbO}_{3}$ and $\mathrm{LiTaO}_{3}$," Applied Physics Letters, vol. 74, no. 13, pp. 1812-1814, 1999.

[27] J. Zhao, D. S. Mao, Z. X. Lin et al., "Intense short-wavelength photoluminescence from thermal $\mathrm{SiO}_{2}$ films co-implanted with Si and C ions," Applied Physics Letters, vol. 73, no. 13, pp. 1838-1840, 1998.

[28] Y. H. Yu, S. P. Wong, and I. H. Wilson, "Visible photoluminescence in carbon-implanted thermal $\mathrm{SiO}_{2}$ films," Physica Status Solidi (A), vol. 168, no. 2, pp. 531-534, 1998.

[29] L. Rebohle, T. Gebel, H. Fröb, H. Reuther, and W. Skorupa, "Ion beam processing for $\mathrm{Si} / \mathrm{C}$-rich thermally grown $\mathrm{SiO}_{2}$ layers: photoluminescence and microstructure," Applied Surface Science, vol. 184, no. 1-4, pp. 156-160, 2001.

[30] O. González-Varona, B. Garrido, A. Pérez-Rodríguez et al., "Analysis of the white emission from ion beam synthesised layers by in-depth resolved scanning photoluminescence microscopy," Materials Science and Engineering B, vol. 91-92, pp. 51-54, 2002.

[31] QI. Zhang, S. C. Bayliss, and W. Frentrup, "The stable blue and unstable UV photoluminescence from carbon nanoclusters embedded in $\mathrm{SiO}_{2}$ matrices," Solid State Communications, vol. 99, no. 12, pp. 883-886, 1996.

[32] T. Ma, J. Xu, J. Du, W. Li, X. Huang, and K. Chen, "Full color light emission from amorphous $\mathrm{SiC}_{x}: \mathrm{H}$ with organicinorganic structures," Journal of Applied Physics, vol. 88, no. 11, pp. 6408-6412, 2000.

[33] R. Salh, L. Fitting, E. V. Kolesnikova et al., "Si and Ge nanocluster formation in silica matrix," Semiconductors, vol. 41, no. 4, pp. 381-386, 2007.

[34] A. Yurtsever, M. Weyland, and D. A. Muller, "Threedimensional imaging of nonspherical silicon nanoparticles embedded in silicon oxide by plasmon tomography," Applied Physics Letters, vol. 89, no. 15, Article ID 151920, 2006. 

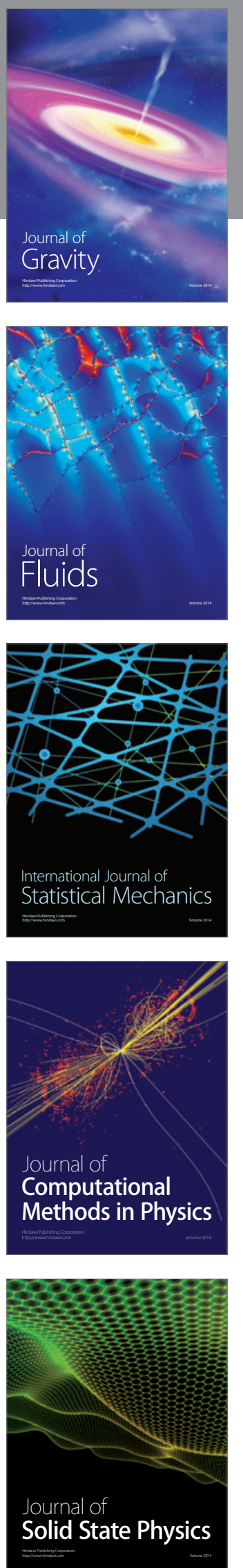

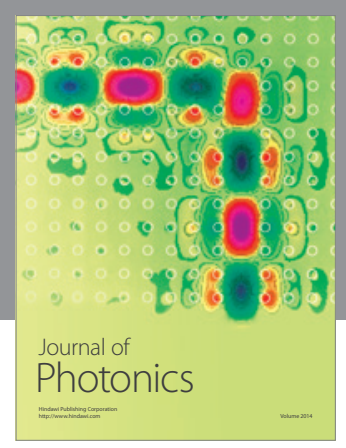

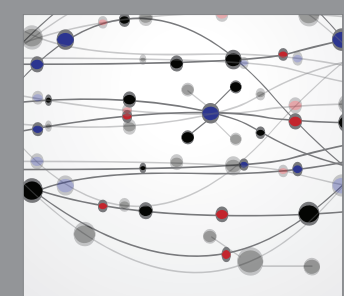

The Scientific World Journal
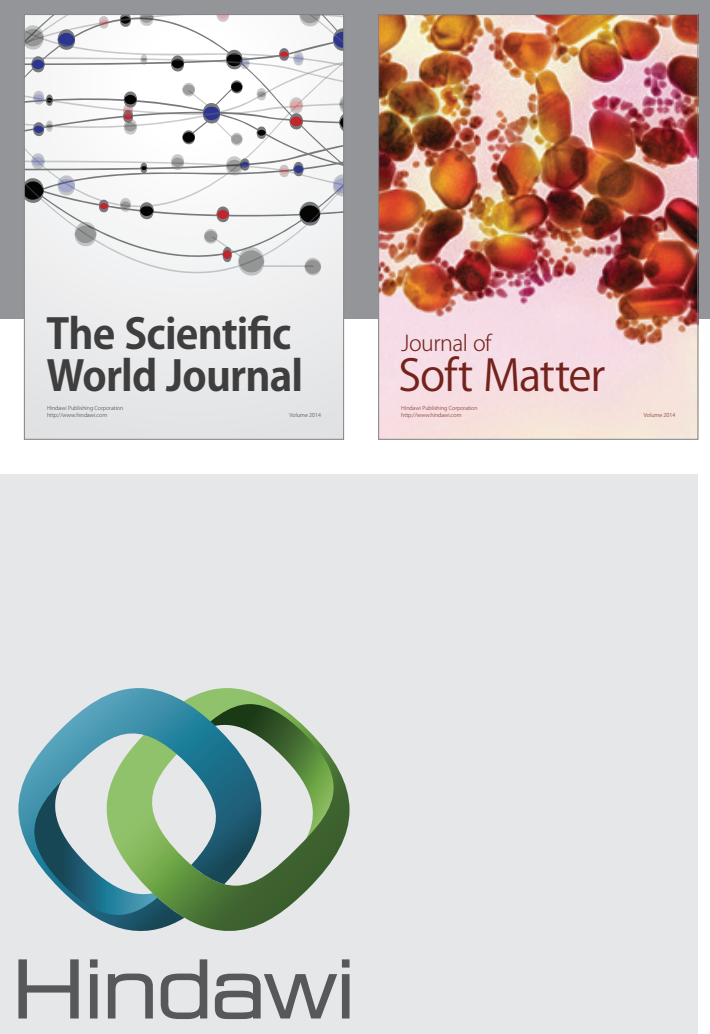

Submit your manuscripts at

http://www.hindawi.com
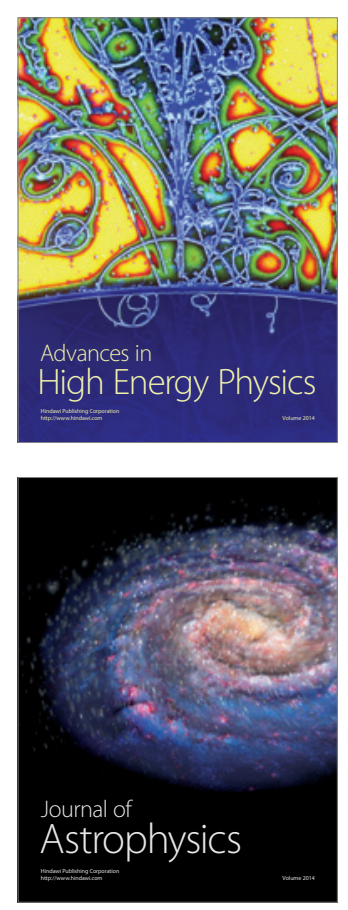
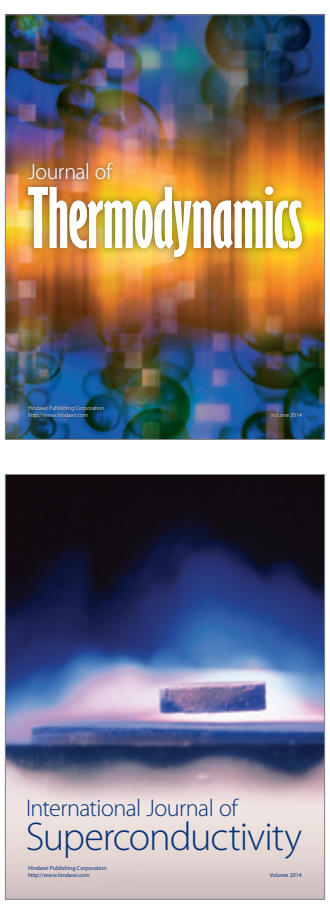
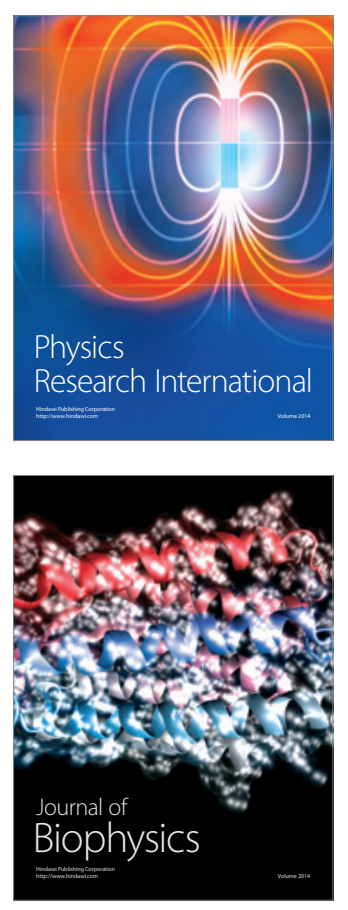
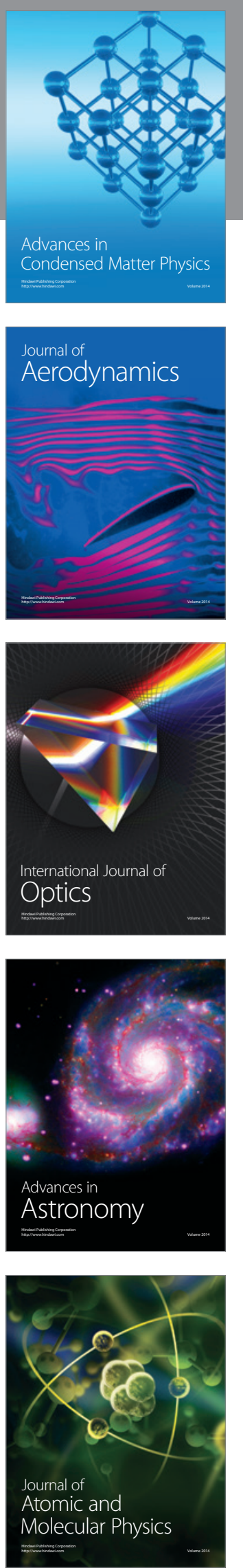